\title{
Morning Glory Syndrome: An Unusual Optic Disc Anomaly
}

\author{
Dr. Elivia N. Sangma ${ }^{1}$,Dr. Poulomi Das ${ }^{1}$,Dr. Anshuman Gahlot ${ }^{1}$ \\ ${ }^{I}$ (Department OfOphthalmology, Regional Institute Of Medical Sciences, Imphal, India)
}

\begin{abstract}
The morning glory disc anomaly is congenital excavation of posterior pole that involves the optic disc. The term reflects the morphological similarity to the flower, the morning glory plant. It is a sporadic condition usually unilateral, though bilateral lesions have been reported. Morning glory discs are more common in females (2:1). The pathogenesis of the condition is unknown. One hypothesis argues that the condition results from failure of closure of the fetal fissure and that it is a variant of optic nerve coloboma. Alternatively, a primary mesenchymal abnormality has been postulated on the basis of the glial tuft, the scleral and vascular abnormalities .It is characterized by funnel-shaped and enlarged dysplastic optic disc with white glial tissue, and retinal vessels arising from the periphery of the disc (spoke wheel pattern) and running an abnormally straight course over the peripapillary retina. Patient can present with visual acuity $6 / 6$ to hand movement. It can cause amblyopia, strabismus even retinal detachment. No definitive treatment is present till date. MGS patients are kept on routine follow up to prevent and treat complications.
\end{abstract}

Keywords: Iris coloboma, Optic disc, Morning Glory Syndrome

\section{Introduction}

A girl aged 16 years presented to the OPD with complaints of painless diminution of vision in left eye since childhood with no previous ocular check-up. On routine ocular examination, Visual Acuity was reduced in left eye to 6160 with supero-temporal iris coloboma and superotemporal subluxation of lens in the same eye. On fundoscopy typical features suggestive of Morning Glory Disc changes were seen.

\begin{tabular}{|c|c|c|}
\hline \multicolumn{3}{|c|}{ Ocular Examination } \\
\hline & OD & OS \\
\hline BCVA & $6 / 6$ & $6 / 60$ \\
\hline AR Finding & $\begin{array}{l}+0.50 \mathrm{DS}-0.50 \\
\text { DC } 180^{\circ}\end{array}$ & $-5.50 \mathrm{DS}-2.0 \mathrm{DC} 180^{\circ}$ \\
\hline Axial Length & 22.36 & 25 \\
\hline Ext. Adnexa & WNL & WNL \\
\hline Ant. Segment & WNL, Orthophoric & WNL,Orthophoric \\
\hline Pupils & $\begin{array}{l}2 \mathrm{~mm}, \text { Reacting To } \\
\text { Light }\end{array}$ & $\begin{array}{l}\text { Peaked Supero Temporally, } \\
\text { Reacting To Light }\end{array}$ \\
\hline Lens & Clear & SubluxatedSuperotemporally \\
\hline IOP & $16 \mathrm{Mmhg}$ & $15 \mathrm{Mm} \mathrm{Hg}$ \\
\hline \multicolumn{3}{|c|}{ FUNDUS EXAMINATION } \\
\hline Media & Clear & Clear \\
\hline Optic Disc & $\begin{array}{l}\text { Normal } \\
\text { Appearance }\end{array}$ & $\begin{array}{l}\text { Large Funnel Shaped } \\
\text { Excavation Of Disc With } \\
\text { White Elevated Hyperplastic } \\
\text { Glial Tissue Occupying } \\
\text { Central Disc }\end{array}$ \\
\hline Vasculature & Normal & $\begin{array}{l}\text { Straight And Radiating From } \\
\text { Disc Margin }\end{array}$ \\
\hline Background & Normal & Normal \\
\hline Macula & Normal & Macular Capture + \\
\hline \multicolumn{3}{|c|}{ SLIT LAMP EXAMINTION } \\
\hline Anterior Segment & Normal & $\begin{array}{l}\text { Iris ColobomaSupero } \\
\text { Temporally (Fig 1) } \\
\text { SubluxatedLens } \\
\text { Superotemporally (Fig 2) }\end{array}$ \\
\hline
\end{tabular}




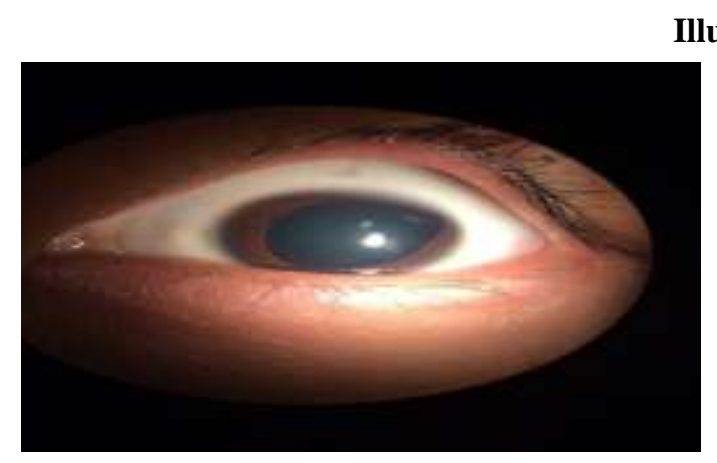

Fig.1 Iris coloboma

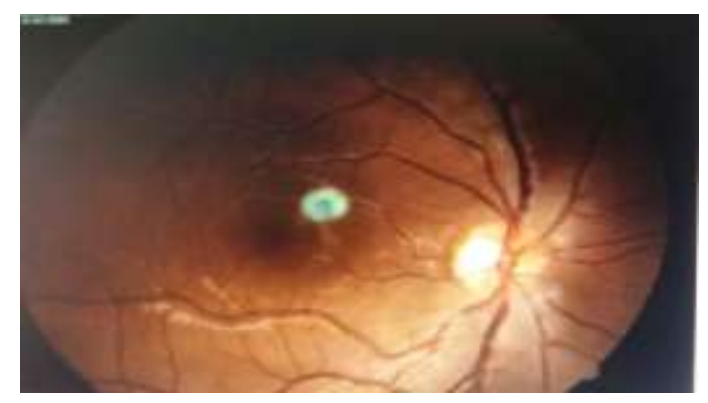

Fig.3 Fundus Photograph OD

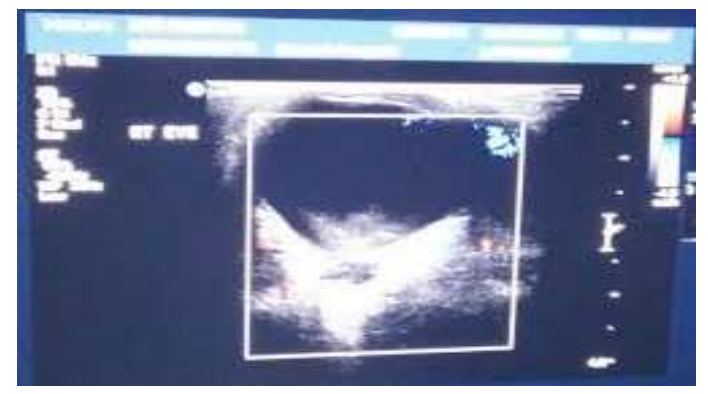

Fig 5 Ultrasound image of posterior pole OD

\section{Illustrations}

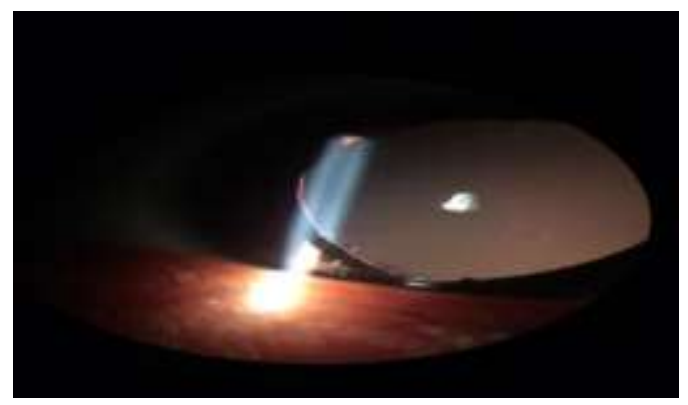

Fig.2Superotemporal subluxation of lens

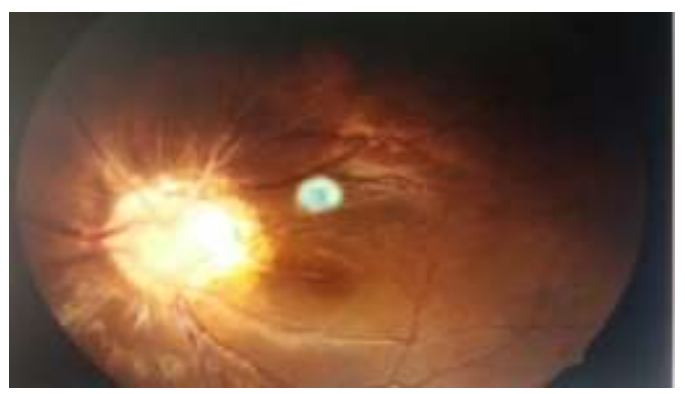

Fig 4 Fundus Photograph OS

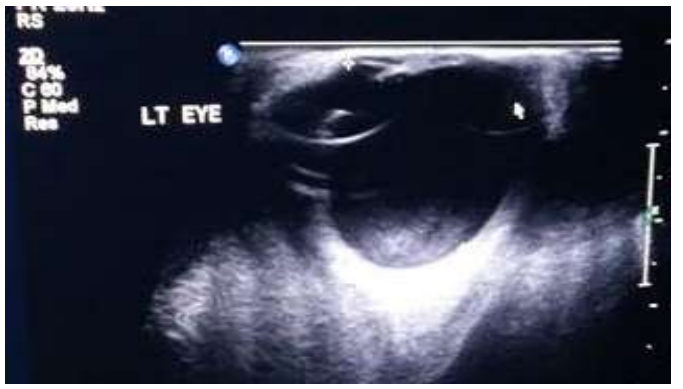

Fig 6 Ultrasound image of posterior pole OS

\section{Conclusion}

Morning glory syndrome is not associated with multi systemic genetic disorder, but can be found along withmany cerebro vascular abnormalities, thus requiring thorough evaluation of the patient. In our patient no other associations were found. There is no proven treatment to prevent the disease with ongoing research aimed at its prevention. In such patients the main concern is to prevent serious complications like retinal detachment, cataract,secondary glaucoma, etc. and to preserve vision in the better eye. Patients should be advised to avoid outdoor activities as much as possible and when this cannot be avoided, they should be advised to wear protective glasses, specially designed to prevent accidental injury of the better eye.Ifpatient is diagnosed early then measures should be aimedat preventing amblyopia or strabismus.

\section{References}

[1]. Brodsky, M.C. 2010. Congenital Optic Disc Anomalies in Pediatric Neuro-ophthalmology. 2nd ed. New York: Springer.

[2]. Lee, BJ and Traboulsi, EI. 2008. Update on the Morning Glory Disc Anomaly. Ophthalmic Genetics 29:2, p47-52.

[3]. Kindler P. Morning glory syndrome: unusual congenital optic disk anomaly. Am J Ophthalmol. 1970; 69(3):376-384

[4]. Dovemedcom. 1. DoveMed. [Online]. Availablettp://www.dovemed.com/morninglory-syndrome [Accessed 13 July 2016].) 